\title{
The effect of sleeping position on heart rate variability in newborns
}

\author{
Petja Fister ${ }^{1}$, Manca Nolimal ${ }^{2}$, Helena Lenasi ${ }^{3}$ and Matjaž Klemenc ${ }^{4 *}$
}

\begin{abstract}
Background: Lower heart rate variability (HRV) in a newborn might represent a risk factor for unfavourable outcome, a longer recovery after illness, and a sudden infant death. Our aim was to determine whether the newborn's sleeping position is associated with HRV.

Methods: We performed a prospective clinical study in 46 hospitalized cardiorespiratory stable term newborns. During sleeping, we measured the parameters of HRV in four body positions (supine, supine with tilt, prone, prone with tilt).

Results: The TP (total power spectral density) was significantly higher when lying supine in comparison to prone $(p=0,048)$ and to prone with tilt $(p=0,046)$. The HF (high frequency of power spectral density) in the supine position without tilt tended to be higher compared to prone without tilt $(p>0,05)$. The LF (low frequency power) was significantly higher when lying supine compared to prone, both without tilt $(p=0,018)$. TP and HF showed a positive correlation with gestational but not postmenstrual age ( $p=0.044$ and $p=0.036$, respectively).
\end{abstract}

Conclusions: In term newborns, sleeping position is associated with HRV. Higher TP and HF were found in the supine position, which might reflect better ANS stability. Gestational age positively correlated with TP and HF power, but only in supine position.

Trial registration: ISRCTN11702082, date of registration: March, 13th, 2020; retrospectively registered.

Keywords: Newborn, Heart rate variability, Sleeping positions, Autonomic nervous system

\section{Background}

Autonomic nervous system (ANS) plays an important role in extrinsic regulation of the heart rate (HR) in newborns. The interplay between the sympathetic and the vagal modulation on the sinoatrial (SA) node could be studied by analysing heart rate variability (HRV). In the frequency domain analysis of HRV, the powers of the low (LF) and high frequency (HF) components of the HRV spectrum have been shown to reflect the degree of ANS modulation on the level of SA node [1]. While the HF is suggested to reflect mainly the vagal

\footnotetext{
* Correspondence: matjaz.klemenc@bolnisnica-go.si

${ }^{4}$ Department of Cardiology, General Hospital Nova Gorica, Nova Gorica, Slovenia

Full list of author information is available at the end of the article
}

modulation, the LF is predominantly influenced by the sympathetic modulation. Frequency domain analysis could be performed in a narrow $(0,04$ to $0,4 \mathrm{~Hz})$ and wider range up to $1 \mathrm{~Hz}$. Because newborns have both, higher heart rate and breathing frequency (BF) than adults, the upper frequency limit of the HF component of power spectral density can be up to $1 \mathrm{~Hz}$. Therefore, wider ranges are usually taken into consideration in newborns. HRV could be regarded as a useful physiological parameter reflecting the responsiveness of the ANS to environmental factors.

Higher HRV might predict a better outcome of illness [2-4]. Massaro et al. conducted a study on 20 newborns with hypoxic ischemic encephalopathy treated with hypothermia and showed that newborns with worse

(c) The Author(s). 2020 Open Access This article is licensed under a Creative Commons Attribution 4.0 International License, which permits use, sharing, adaptation, distribution and reproduction in any medium or format, as long as you give appropriate credit to the original author(s) and the source, provide a link to the Creative Commons licence, and indicate if changes were made. The images or other third party material in this article are included in the article's Creative Commons licence, unless indicated otherwise in a credit line to the material. If material is not included in the article's Creative Commons licence and your intended use is not permitted by statutory regulation or exceeds the permitted use, you will need to obtain permission directly from the copyright holder. To view a copy of this licence, visit http://creativecommons.org/licenses/by/4.0/. The Creative Commons Public Domain Dedication waiver (http://creativecommons.org/publicdomain/zero/1.0/) applies to the data made available in this article, unless otherwise stated in a credit line to the data. 
neurological outcome (death in neonatal period or Bayley Developmental Index scores $>2 \mathrm{SD}$ below the mean at 15-month follow-up) had lower HRV [4]. Lower HRV is suggested to be one of the risk factors for longer recovery after illness [2] and an index of illness severity [2, 5-7]. Griffin et al. showed that a sudden fall of HRV might be used as an early marker of sepsis [6]. Moreover, preterms and newborns with congenital heart anomalies exhibit lower HRV. Butera et al. found reduced HRV parameters in 4-7-year-old children with tetralogy of Fallot who underwent surgery at the age of 2 years in comparison to controls [8]. Moreover, Faye et al. showed that newborns with high levels of pain assessment score postoperatively exhibited lower high frequency variability and therefore, lower HRV in comparison with those with lower values of pain assessment score [9]. Snedec et al. discovered that TP values inversely correlated with the duration of intensive care unit treatment of critically ill newborns and the duration of mechanical ventilation needed [10]. They also suggested that lower HRV parameters during transport could imply their response to stress. HRV analysis might thus be used as a measure to estimate the severity of illness and newborn's response to stress [2, 10-13].

Lower HRV has also been suggested to be one of the risk factors for sudden infant death syndrome (SIDS) [14-18]. In addition, sleeping position has been reported to be related to SIDS. Moreover, sleeping position also affected cerebral oxygenation in stable preterms: it was higher in the supine than in the prone position $[13,15]$.

In the literature, only little information regarding potential correlation between the sleeping position and $\mathrm{HRV}$ is available. Ariagno et al. studied 16 preterms at 1- and 3-months' corrected age, respectively and found significantly lower HRV in time domain analysis in prone position during quiet sleep [19].

Accordingly, the aim of our study was to determine the association of sleeping position on HRV analysed by frequency domain analysis. We also studied potential association between blood oxygenation, breathing frequency (BF), mean arterial blood pressure (MAP) and HRV parameters in different sleeping positions and the correlation between gender, gestational and postmenstrual age (PMA) and any parameters of HRV. We hypothesized that the parameters of HRV might be more favourable for outcome in supine position compared to prone, even more so with tilt.

\section{Methods}

\section{Patients}

We conducted a prospective clinical intervention study on 46 cardiovascular and respiratory stable newborns who had no respiratory and/or hemodynamic support. The newborns were hospitalized at the Neonatal
Department of the Division of Paediatrics, University Medical Centre Ljubljana, Slovenia, due to diagnostic procedures. Newborns with hypoxic ischemic encephalopathy (HIE), preterms, and newborns with infection, neurological or congenital abnormalities were excluded. The parents gave their informed consent and the study was approved by the National Ethics Committee (0120458/2016-3 KME 67/09/16). The investigation conforms to the principles outlined in the Declaration of Helsinki.

\section{Study setting}

Before feeding, we installed electrodes to the newborn's chest. After feeding, we put sleeping newborns in supine position with a $30^{\circ}$ head-up tilt of the bed for $30 \mathrm{~min}$. We recorded ECG signal in four positions: the supine without and with tilt and prone with and without tilt (Fig. 1) by using ECG Holter system (Vision 5 L, Burdick, USA). We recorded parameters in every position for at least 30 min, when the newborn was sleeping quietly. Simultaneously, we assessed newborn's alertness using five stage description [20]. In all positions, the BF was counted (by visualizing the excursions of the thorax) and HR and blood oxygenation measured by pulse oximeter (Intelli Vue MP 50, Philips, Germany) 10 min after changing the lying position of the newborn. Blood pressure (systolic and diastolic) was measured noninvasively using inflatable cuff. Body temperature was measured by infrared non-contact frontal thermometer Veratemp + (Veratemp; USA).

\section{Data analysis}

ECG recordings were analysed by Nevrokard HRV Analysis software (Nevrokard, Izola, Slovenia). The acquired data were checked by a cardiologist and artefacts were excluded. The RR intervals (intervals between two subsequent R-waves of the QRS complex) measured before and after an ectopic beat were replaced by two interpolated RR intervals, which were calculated from a proceeding and a succeeding sinus interval. A fast Fourier transformation (FFT) was used for spectral analysis of HRV. Spectral analysis of HRV was performed in two different frequency ranges, namely from 0,04 to $0,4 \mathrm{~Hz}$ (narrow spectrum) and from 0,04 to $1,0 \mathrm{~Hz}$ (wide spectrum), the latter because of high $\mathrm{BF}$ in newborns. Recording periods of $256 \mathrm{~s}$ were analysed, each yielding 512 data points after re-sampling at the $2 \mathrm{~Hz}$ frequency. The Hamming windowing function was applied and the Goertz algorithm was used for calculation.

We determined the spectral densities of the narrow spectrum in three different frequency bands: 0,0033-0, $04 \mathrm{~Hz}$ (very low frequency power - VLF), $0,04-0,15 \mathrm{~Hz}$ (low frequency power - LF), and $0,15-0,4 \mathrm{~Hz}$ (high frequency power - HF). Likewise, the wider spectrum was divided in three frequency ranges: $0,0033-1,0 \mathrm{~Hz}$ (TP - 


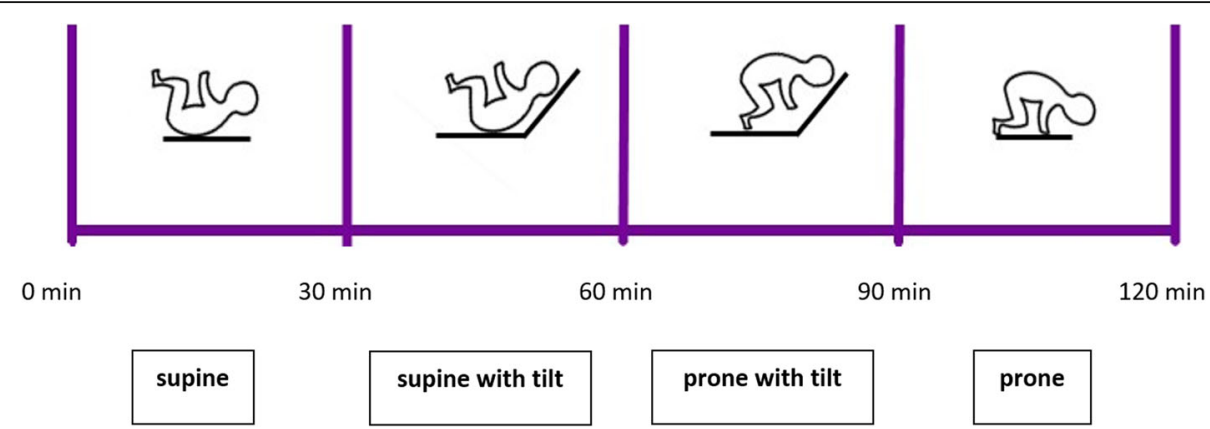

Fig. 1 Timeline of the study protocol. After feeding, we started the measurements and the neonate was put in the bed lying supine. Every 30 min the neonate's position was changed

total power), $0,04-0,15 \mathrm{~Hz}$ (low frequency power - LF), and $0,15-1,0 \mathrm{~Hz}$ (high frequency power - HF) [21]. According to the recommendations of Task Force of European Society of Cardiology and North American Society of Pacing and Electrophysiology [22-24], LF and HF were reported as ratio and in normalized units (LFnu, HFnu), and each component was expressed relatively to the whole HRV spectrum meaning that the VLF component was subtracted LFnu $=\mathrm{LF} /($ total $-\mathrm{VLF}) ; \mathrm{HFnu}=$ $\mathrm{HF} /($ total - VLF).

\section{Statistical analysis}

The normality of the sample was tested by Shapiro-Wilk normality test using significance level of 0,05 . The descriptive statistics were reported, and the numerical variables summarized as means and standard deviations (SD). The association of the body position with the HRV was verified by the Friedman's nonparametric test and the post-hoc Wilcoxon tests. For controlling for PMA we have calculated the related samples Friedman's 2-way analysis of variance by ranks. We used the correction factor by Benjamini and Hochberg for control of false discovery rate in all analyses [25]. The relationship between blood oxygen saturation, BF, MAP, gender, age, and HRV parameters were analysed by Spearman's correlation coefficient. Adjusted P smaller than 0,05 was considered statistically significant. The statistical analysis was performed by the IBM SPSS Statistics ver. 23.0 software.

\section{Results}

We analysed the data of 46 newborns, 31 (67\%) were boys. Because of the missing or inappropriate data, we excluded 5 newborns (1 girl and 4 boys). Demographic data are shown in Table 1 and descriptive statistics of MAP, HR, BF, arterial blood oxygen saturation and temperature are shown in Table 2.

We did not find any significant differences between the individual HRV parameters relative to the spectrum frequency limits; Tables 3 and 4 show the analyses of the wide- and narrow spectrum, respectively. We found significant differences in the TP between supine and prone position $(p=0,048)$ and between supine position and prone position with tilt $(\mathrm{p}=0,046)$. The TP was significantly lower when lying prone in comparison to supine (Table 3).

The HF values in the supine position tended to be higher compared to the prone, but not significantly $(p>$ 0,05 , Table 3 ). LF was significantly higher in both supine compared to prone $(p=0,018$, Table 3$)$. LF was also significantly higher in supine with tilt compared to prone $(p=0,036$, Table 3). The ratio of the LF and HF tended to be higher in supine in comparison to prone $(\mathrm{p}=0$, 039, Table 3).

No correlations between blood oxygen saturation, BF, MAP and HRV parameters were found. Significantly lower blood oxygen saturation and BF were found when lying prone in comparison with supine $(\mathrm{p}=0,002$, Table 2).

We found no correlation between gender and any parameters of HRV. Significant correlations between gestational age and the parameters of HRV were found only in supine (but no other) position: gestational age was positively correlated with TP $(\mathrm{R}=0.348, p=0.0449)$, HFnu $(\mathrm{R}=0.350, p=0.036)$ and negatively with LFnu $(\mathrm{R}=-0.342, \mathrm{p}=0.044)$ (Fig. 2). After considering the PMA of each newborn, none of the HRV parameters correlated to the PMA.

Table 1 Perinatal characteristics of the newborns

\begin{tabular}{ll}
\hline $\mathbf{N = 4 6}$ & Mean \pm SD \\
\hline Gestational age (weeks) & $39 \pm 1$ \\
Postnatal age (days) & $11 \pm 7$ \\
Birth weight (g) & $3440 \pm 453$ \\
Head circumference (cm) & $34,9 \pm 1,5$ \\
Apgar score 10 min & $9,5 \pm 0,8$ \\
\hline
\end{tabular}


Table 2 Descriptive statistics of the measured physiological parameters in different sleeping positions

\begin{tabular}{|c|c|c|c|c|c|c|}
\hline & Supine (S) & Supine with tilt (ST) & Prone with tilt (PT) & Prone $(\mathrm{P})$ & p value ${ }^{\mathbf{a}}$ & $p$ value $^{\mathbf{b}}$ \\
\hline Arterial blood oxygen saturation (\%); Median (IQR) & $\begin{array}{l}97,0 \\
(96,0-98,3)\end{array}$ & $\begin{array}{l}97,0 \\
(96,0-98,0)\end{array}$ & $\begin{array}{l}96,0 \\
(96,0-97,5)\end{array}$ & $\begin{array}{l}96,0 \\
(95,0-97,0)\end{array}$ & $p=0,001$ & $\begin{array}{l}S \text { vs } S T=0,847 \\
\text { ST vs } P T=0,009^{*} \\
\text { PT vs } P=0,037^{*} \\
\text { S v } P=0,004^{*} \\
\text { S vs } P T=0,014^{*} \\
\text { ST vs } P=0,001^{*}\end{array}$ \\
\hline $\begin{array}{l}\text { Heart rate (/min) } \\
\text { Median (IQR) }\end{array}$ & $\begin{array}{l}136,5 \\
(122,3-145,0)\end{array}$ & $\begin{array}{l}134,0 \\
(128,0-143,0)\end{array}$ & $\begin{array}{l}132,5 \\
(124,0-141,3)\end{array}$ & $\begin{array}{l}130,0 \\
(120,0-138,0)\end{array}$ & $p=0,238$ & NS \\
\hline Breathing frequency (bpm) Median (IQR) & $47(44-50)$ & $\begin{array}{l}47 \\
(45-50)\end{array}$ & $45(43-49)$ & $\begin{array}{l}45 \\
(42,0-47,5)\end{array}$ & $p=0,001$ & $\begin{array}{l}\text { S vs } S T=0,039^{*} \\
\text { ST vS } P T=0,001^{*} \\
\text { PT vs } P=0,045^{*} \\
\text { S vs } P=0,001^{*} \\
\text { S vs } P T=0,025^{*} \\
\text { ST vs } P=0,001^{*}\end{array}$ \\
\hline Systolic arterial pressure (mmHg) Median (IQR) & $\begin{array}{l}71,0 \\
(62,8-78,3)\end{array}$ & $\begin{array}{l}73,0 \\
(68,5-82,0)\end{array}$ & $\begin{array}{l}72,0 \\
(66,0-79,0)\end{array}$ & $\begin{array}{l}72,0 \\
(67,0-80,0)\end{array}$ & $p=0,334$ & NS \\
\hline Diastolic arterial pressure $(\mathrm{mmHg})$ Median (IQR) & $\begin{array}{l}42,5 \\
(37,5-46,0)\end{array}$ & $\begin{array}{l}45,0 \\
(40,0-50,0)\end{array}$ & $\begin{array}{l}41,0 \\
(37,0-46,5)\end{array}$ & $\begin{array}{l}44,0 \\
(40,0-50,0)\end{array}$ & $p=0,637$ & NS \\
\hline Mean arterial pressure $(\mathrm{mmHg})$ Median (IQR) & $\begin{array}{l}51,0 \\
(47,0-57,0)\end{array}$ & $\begin{array}{l}54,0 \\
(49,5-59,5)\end{array}$ & $\begin{array}{l}52,0 \\
(47,3-54,0)\end{array}$ & $\begin{array}{l}54,0 \\
(48,0-60,0)\end{array}$ & $p=0,179$ & NS \\
\hline Temperature $\left({ }^{\circ} \mathrm{C}\right)$ Mean $(\mathrm{SD})$ & $36,6 \pm 0,04$ & $36,6 \pm 0,04$ & $36,6 \pm 0,04$ & $36,6 \pm 0,04$ & & NS \\
\hline
\end{tabular}

${ }^{\mathrm{a}}$ Friedman test

${ }^{\mathrm{b}}$ Willcoxon signed rank test

${ }^{*} p$ values < 0,05 (False discovery rate - FDR; corr. Factor Benjamini and Hochberg)

NS: non- significant

Data are presented as median value and IQR (interquartile range), except for the temperature data which are means+/- SD. In the last collon, statistical differences

between two positions are presented

\section{Discussion}

The salient finding of our study is that the term newborn's sleeping position is associated with HRV as analysed by frequency domain spectral analysis. TP and LF in term newborns are both higher when lying supine in comparison to prone position which might imply an increased responsiveness of the ANS in supine position. To the best of our knowledge, this is the first study that evaluated the effect of sleeping position on HRV analysed by frequency domain spectral analysis in term newborns.

Only little information is available regarding the impact of ANS on the cardiovascular regulation in newborns. Findings show that the activity of the ANS increases with PMA mainly in terms of an increase of reflex vagal activity [26-29]. On the other hand, clinical studies conducted in preterms show greater sympathetic activity, higher HR and less expressed vagal activity as compared to term newborns [27, 28, 30,31].

In our study, newborns had higher TP HRV when lying supine compared to prone position. Also, the LF was significantly higher in supine in comparison to prone position. Since LF spectrum is supposed to reflect the sympathetic activity [26], we can assume that the cardiac sympathetic modulation is less pronounced in prone position. Similarly, Gabai et al. found reduced HRV parameters analysed in time domain in three-day old term newborns in a prone position [32]. In prone position, they showed a decrease in SDNN (standard deviation of normal R-R) which correlated with TP and also a decrease in short term variability (assessed by pNN50) which correlated with HF. No effect of birthweight or gestational age on HRV was noted in their study. Similar to our study, Jean-Luis et al. also found both, TP and LF to be significantly higher in supine compared to prone position. Also, similar to our observation, no significant difference was seen in HF [33]. Moreover, Galland et al. also showed lower HRV assessed by the point dispersion of Poincaré plots in prone position in term infants [34]. On the other hand, Ariagno et al. found lower HRV in prone position only in the time domain, but not in the frequency domain: RMSSD (the square root of the mean of the sum of the squares of differences between adjacent R-R), which corresponds to HF was significantly greater in the supine position at both 1 and 3 months' corrected age, whereas the SDNN was significantly higher in the supine position, but only at 1 month corrected age [19]. These results on increased HF are in agreement with the results of our study and, besides the above speculated sympathetic influence, imply also an important contribution of vagal baroreflex modulation.

Besides assessing the parameters of HRV, we have simultaneously measured the arterial oxygen saturation and BF what was not performed in other available studies. Blood oxygen saturation was significantly lower in 
Table $3 \mathrm{HRV}$ parameters in different positions in the wide frequency range $0.04 \mathrm{~Hz}-1 \mathrm{~Hz}$

\begin{tabular}{|c|c|c|c|c|c|c|c|}
\hline & $\begin{array}{l}\text { supine } \\
(\mathrm{S})\end{array}$ & supine with tilt (ST) & prone with tilt (PT) & $\begin{array}{l}\text { prone } \\
(\mathrm{P})\end{array}$ & $p$ value ${ }^{a}$ & $p$ value $^{\mathbf{b}}$ & $p$ value \\
\hline $\begin{array}{l}\mathrm{TP}\left(\mathrm{ms}^{2}\right) \text { Median } \\
\text { (IQR) }\end{array}$ & $\begin{array}{l}596,5 \\
(395,3-1021,5)\end{array}$ & $\begin{array}{l}833,7 \\
(251,9-1592,8)\end{array}$ & $\begin{array}{l}406,0 \\
(249,0-580,0)\end{array}$ & $\begin{array}{l}327,0 \\
(133,5-715,3)\end{array}$ & $p=0,026$ & $\begin{array}{l}\text { S vs } S T=0,387 \\
\text { ST vs } P T=0,17 \\
\text { PT vs } P=0,24 \\
S \text { vs } P T=0,046^{*} \\
S \text { vs } P=0,048^{*} \\
\text { ST vs } P=0,036^{*}\end{array}$ & $p=0,018$ \\
\hline $\begin{array}{l}\text { HF - }\left(\mathrm{ms}^{2}\right) \text { Median } \\
\text { (IQR) }\end{array}$ & $\begin{array}{l}113,5 \\
(60,0-214,8)\end{array}$ & $\begin{array}{l}111,5 \\
(50,0-238,5)\end{array}$ & $\begin{array}{l}103,0 \\
(47,0-173,0)\end{array}$ & $\begin{array}{l}93,1 \\
(58,0-237,0)\end{array}$ & $p=0,250$ & & $p=0,007$ \\
\hline HF nu - Median (IQR) & $30,2(23,3-45,8)$ & $33,8(22,1-53,4)$ & $38,3(23,5-51,3)$ & $49,1(28,8-68,5)$ & $p=0,06$ & & $p=0,021$ \\
\hline $\begin{array}{l}\mathrm{LF}-\left(\mathrm{ms}^{2}\right) \text { Median } \\
(\mathrm{IQR})\end{array}$ & $\begin{array}{l}256,0 \\
(150,0-379,8)\end{array}$ & $\begin{array}{l}298,5 \\
(85,7-428,5)\end{array}$ & $\begin{array}{l}147,0 \\
(107,4-301,0)\end{array}$ & $\begin{array}{l}185,5 \\
(60,3-295,8)\end{array}$ & $p=0,015$ & $\begin{array}{l}\text { S vs } S T=0,552 \\
\text { ST vs } P T=0,484 \\
\text { PT vs } P=0,106 \\
S \text { vs } P=0,019^{*} \\
S \text { vs } P T=0,261 \\
\text { ST vs } P=0,036^{*}\end{array}$ & $p=0,738$ \\
\hline $\begin{array}{l}\text { LF nu - Median } \\
\text { (IQR) }\end{array}$ & $68,9(52,9-77,8)$ & $66,9(56,5-78,6)$ & $62,7(53,0-77,9)$ & $50,7(31,6-71,2)$ & $p=0,034$ & $\begin{array}{l}S \text { vs } S T=0,795 \\
\text { ST vs } P T=0,75 \\
P T \text { vs } P=0,123 \\
S \text { vs } P=0,06 \\
S \text { vs } P T=0,987 \\
\text { ST vs } P=0,136\end{array}$ & $p=0,576$ \\
\hline $\begin{array}{l}{\mathrm{LF} / H F^{5}}^{5} \text { Median } \\
\text { (IQR) }\end{array}$ & $\begin{array}{l}2,4 \\
(1,2-3,4)\end{array}$ & $\begin{array}{l}1,97 \\
(1,20-3,61)\end{array}$ & $\begin{array}{l}1,61 \\
(1,03-3,31)\end{array}$ & $\begin{array}{l}1,04 \\
(0,46-2,48)\end{array}$ & $p=0,039$ & $\begin{array}{l}S \text { vs } S T=0,77 \\
S T \text { vs } P T=0,78 \\
P T \text { vs } P=0,12 \\
S \text { vs } P=0,24 \\
S \text { vs } P T=0,9 \\
S T \text { vs } P=0,15\end{array}$ & \\
\hline
\end{tabular}

${ }^{\mathrm{a}}$ Friedman test

${ }^{\mathrm{b}}$ Willcoxon signed rank test

'Related-Samples Friedman's Two-Way Analysis of Variance by Ranks

${ }^{*} p$ values $<0,05$ (False discovery rate - FDR; corr. Factor Benjamini and Hochberg)

$I Q R$ - interquartile range; $H R V$ - heart rate variability, $T P$ - total power; $H F$ - high frequency power; $L F-$ low frequency; ${ }^{\S} L F / H F-$ ratio of the $L F$ and $H F$

Table 4 HRV parameters in different positions in the narrow frequency range $(0,04-0,4 \mathrm{~Hz})$

\begin{tabular}{|c|c|c|c|c|c|c|}
\hline & $\begin{array}{l}\text { supine } \\
(\mathrm{S})\end{array}$ & supine with tilt (ST) & prone with tilt (PT) & $\begin{array}{l}\text { prone } \\
(\mathrm{P})\end{array}$ & $p$ value ${ }^{a}$ & $p$ value ${ }^{\mathbf{b}}$ \\
\hline $\begin{array}{l}\mathrm{TP}\left(\mathrm{ms}^{2}\right) \text { Median } \\
(\mathrm{IQR})\end{array}$ & $498,5(318-937,5)$ & $581,1(171,4-1105,0)$ & $305,2(212,0-473,0)$ & $253,3(105,0-634,8)$ & $p=0,026$ & $\begin{array}{l}S \text { vs } S T=0,92 \\
S T \text { vs } P T=0,42 \\
P T \text { vs } P=0,29 \\
S \text { vs } P=0,06 \\
S \text { vs } P T=0,08 \\
S T \text { vs } P=0,09\end{array}$ \\
\hline $\begin{array}{l}\mathrm{HF}-\left(\mathrm{ms}^{2}\right) \text { Median } \\
(\mathrm{IQR})\end{array}$ & $48,5(28,8-104,3)$ & $51,0(19,1-116,0)$ & $45,0(22,0-69,4)$ & $46,0(22,5-77,8)$ & $p=0,081$ & \\
\hline HF nu Median (IQR) & $17,35(12,68-26,13)$ & $17,9(13,8-24,4)$ & $20,7(14,7-25,6)$ & $22,5(16,1-36,1)$ & $p=0,053$ & \\
\hline $\begin{array}{l}\mathrm{LF}-\left(\mathrm{ms}^{2}\right) \text { Median } \\
(\mathrm{IQR})\end{array}$ & $256(150-379,8)$ & $293,0(85,7-293,0)$ & $142,0(96,0-301,0)$ & $174,5(54,8-295,8)$ & $p=0,015$ & $\begin{array}{l}S \text { vs } S T=0,46 \\
\text { ST vs } P T=0,047^{*} \\
P T \text { vs } P=0,01^{*} \\
S \text { vs } P=0,03^{*} \\
S \text { vs } P T=0,15 \\
S T \text { vs } P=0,028^{*}\end{array}$ \\
\hline LF nu Median (IQR) & $82,7(64,6-87,6)$ & $79,6(65,1-86,2)$ & $78,3(73,0-85,3)$ & $72,2(55,9-83,0)$ & $p=0,174$ & \\
\hline $\begin{array}{l}\mathrm{LF} / \mathrm{HF}^{\S} \text { Median } \\
\text { (IQR) }\end{array}$ & $4,7(2,3-7,1)$ & $4,3(3,1-6,2)$ & $3,6(2,8-5,8)$ & $2,72(1,8-4,9)$ & $p=0,039$ & $\begin{array}{l}S \text { vs } S T=0,922 \\
S T \text { vs } P T=1,04 \\
P T \text { vs } P=0,29 \\
S \text { vs } P=0,144 \\
S \text { vs } P T=0,975 \\
S T \text { vs } P=0,162\end{array}$ \\
\hline
\end{tabular}

${ }^{\mathrm{a}}$ Friedman test

${ }^{\mathrm{b}}$ Willcoxon signed rank test

${ }^{*} p$ values $<0,05$ (False discovery rate - FDR; corr. Factor Benjamini and Hochberg)

$I Q R$ - interquartile range; HRV - heart rate variability, TP - total power; HF - high frequency power; LF - low frequency; ${ }^{\S} L F / H F-$ ratio of the $L F$ and $H F$ 

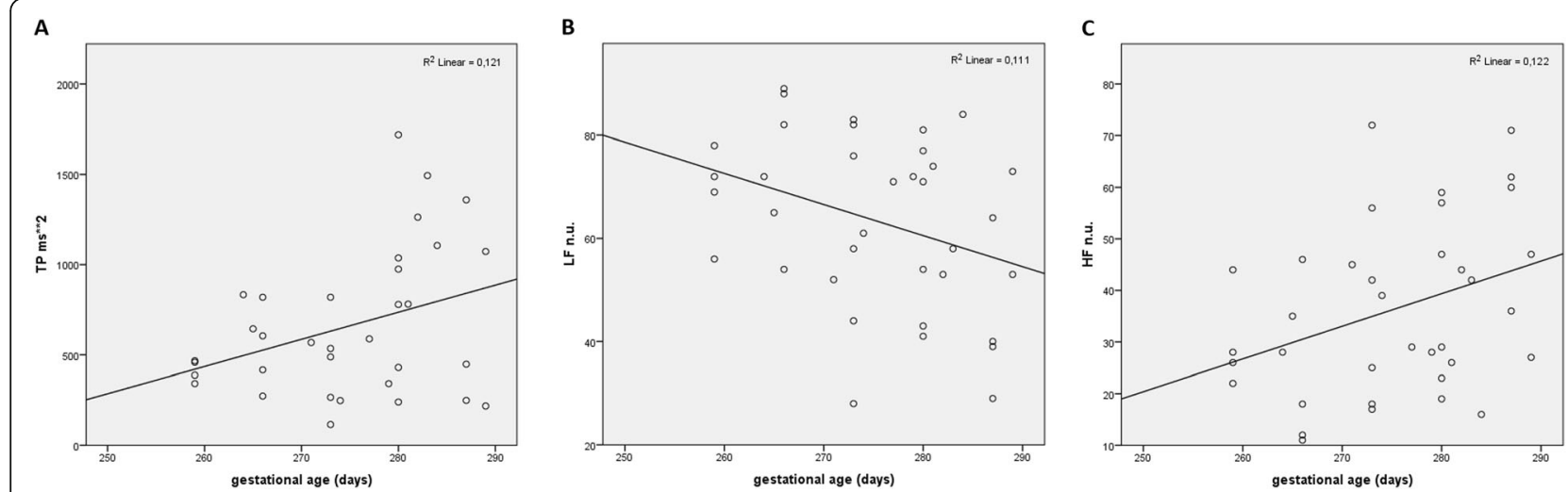

Fig. 2 Correlation between: a total power (TP) and gestational age, b low frequency (normalized units - HFnu) and gestational age and $\mathbf{c}$ high frequency (normalized units - LFnu) and gestational age in newborns. Pearson's correlation coefficients and 2-tailed significances: a: 0,348 ( $p=$ $0,044)$, b: $-0,342(p=0,044)$ and $\mathbf{c :} 0,35(p=0,036)$. Measurements in supine position

prone compared to supine although not clinically important, since in both positions, the measured saturation was above $94 \%$. On the contrary, it has been reported that preterms receiving nasal continuous positive airway pressure (nCPAP) for mild respiratory failure had better arterial blood oxygenation when lying prone [35]. In newborns who were without non-invasive support, we have also observed lower BF when lying prone. Yet, both physiological parameters were within normal limits (BF of the newborn 30-60/min) in both positions and could imply greater impact of the parasympathetic nervous system in prone position [36, 37].

We did not find any correlation between gender and either parameter of the HRV which is in accordance with the findings of Javorka et al. and Yanget al [26, 38].. On the other hand, Nagy et al. found significantly lower HR and lower HRV, expressed as the standard deviation of the HR, in boys [39]. Male newborns had a significantly decreased pNN50 (namely HF) compared to females when lying prone [32].

In our study, newborn's gestational age but not PMA positively correlated with TP and HF power and negatively with LF power when lying supine but not when lying prone although there is a large variability in the data as shown by the very low $\mathrm{R}$-squared values. Our observations are in accordance with the finding of the Cardoso et al. [40] who have shown higher HRV in older newborns. Gestational age as well as PMA have been shown to be positively correlated with $\operatorname{HF}$ and negatively with $\operatorname{LF}[3,28,29,41]$. These findings might implicate that the vagal activity increases with PMA, while the sympathetic modulation of HRV in neonates seems to be less expressed. Chatow et al. confirmed that LF/HF ratio decreases with advanced PMA. Vagal tonus increases with gestational age [42].
Friedman et al. showed that at term, the cardiovascular system is not fully mature yet, and the development continues for several weeks after birth [43]. Bar-Haim et al. found an increase in HF power spectral density also in the period between 4 and 48 months of postnatal age [31]. We might imply that during the period between 37 th to 41 st weeks the vagal influence becomes more expressed. Interestingly, the correlation between gestational age and the parameters of HRV was significant only in supine position in our study.

Impaired regulation of the cardiovascular system is one of the most important risk factors for SIDS. In infants who later suffered from SIDS, a higher HR and lower HRV were found [44]. Decreased ANS responsiveness has been suggested to contribute to an increased risk for SIDS in infants sleeping in the prone position [16]. In our study, we did not find any significant differences in basal HR in different sleeping positions. On the other hand, we found higher TP and LF in supine position. According to our results we may speculate that sleeping in a supine position could have some advantages in prevention of SIDS.

Besides parameters of HRV, increased arterial blood oxygen saturation in supine additionally speaks in favour of supine over prone position, which is in concordance with some previous studies [12, 15]. Fyfe et al. discovered that cerebral perfusion in preterm infants was significantly lower when lying prone compared with supine in both - active and quiet sleep stages. In accordance with our study, they found lower blood oxygen saturation in newborns when lying prone during a quite sleep at 2 to 4 weeks and at 5 to 6 months of age $(P<0,05)[15]$.

A potential limitation of our study is an intermittent and not a continuous measuring of the BF, MAP, and lack of electroencephalographic data of the sleep stages. 
Second limitation is a rather small sample size: had we had a larger sample, we could have compared more variables such as the Apgar score, and the type of the childbirth to the variables of HRV. Additional limitation is a rather heterogeneous PMA of the included newborns at the time of the HRV measurement. Yet, as all newborns were older than 5 days, we might assume that they have already overcome the transitional period of hemodynamic adaptations. It might be possible that the sequence in which the positions were applied could be a confounding variable, but to test this hypothesis, too many possible variants should have been tested so we decided for the decribed protocol.

\section{Conclusion}

Our study showed that newborn's sleeping position is associated with HRV. Higher TP and LF of the HRV analysed in the frequency domain were found in the supine position, reflecting ANS stability. We found a positive correlation between newborn's gestational age and TP and HF and a negative correlation with the LF in supine, implying an important contribution of the vagal modulation of the HR in supine position. The study might imply that the newborn's supine position is more favourable in comparison to prone, at least with regard to HRV.

\section{Abbreviations \\ ANS: autonomic nervous system; HF: high frequency power spectrum; HRV: heart rate variability; LF: low frequency power spectrum; TP: total power; SIDS: sudden infant death syndrome; PMA: postmenstrual age; nu: normalized units}

\section{Acknowledgements}

Not applicable.

\section{Authors' contributions}

All authors collaborated and conceptualized the study, drafted the initial manuscript, and reviewed and revised the manuscript. PF coordinated the clinical conduction of the research. MN conducted clinical research and methodologically analysed the data. HL critically revised the manuscript for important physiological content. MK performed spectral analysis of heart rate variability. All authors revised and approved the final manuscript as submitted and agree to be accountable for all aspects of the work.

\section{Funding}

There is no funding source.

\section{Availability of data and materials}

All data generated or analysed during this study are included in this published article [and its supplementary information files].

\section{Ethics approval and consent to participate}

The study has been approved by National ethics committee of Slovenia (0120-458/2016-3 KME 67/09/16) and has been performed in accordance with the ethical standards as laid down in the 1964 Declaration of Helsinki and its later amendments or comparable ethical standards. Parents of all participating newborns gave their written informed consent.

\section{Consent for publication}

Not applicable.

\section{Competing interests}

Authors have no financial relationships relevant to this article to disclose.

\section{Author details}

'Division of Paediatrics, Department of Neonatology, University Medical Centre Ljubljana, Ljubljana, Slovenia. ${ }^{2}$ University Medical Centre Ljubljana, Ljubljana, Slovenia. ${ }^{3}$ Institute of Physiology, Medical Faculty, University of Ljubljana, Ljubljana, Slovenia. ${ }^{4}$ Department of Cardiology, General Hospital Nova Gorica, Nova Gorica, Slovenia.

Received: 9 September 2019 Accepted: 30 March 2020

Published online: 13 April 2020

\section{References}

1. Malliani A, Lombardi F, Pagani M. Power spectrum analysis of heart rate variability: a tool to explore neural regulatory mechanisms. Br Heart J. 1994; 71:1-2. https://doi.org/10.1126/science.6166045.

2. Goldstein B, Fiser DH, Kelly MM, Mickelsen D, Ruttimann U, Pollack MM. Decomplexification in critical illness and injury: relationship between heart rate variability, severity of illness, and outcome. Crit Care Med. 1998;26(2): 352-7 http://eutils.ncbi.n/m.nih.gov/entrez/eutils/elink.fcgi?dbfrom= pubmed\&id $=9468175 \&$ retmode $=$ ref\&cmd=prlinks\%5Cnpapers2:// publication/uuid/9792D085-DA14-496C-9287-810A4A56CE42.

3. Longin E, Schaible T, Demirakca S, Lenz T, König S. Heart rate variability during extracorporeal membrane oxygenation and recovery in severe neonatal disease. Early Hum Dev. 2006;82(2):135-42. https://doi.org/10.1016/ j.earlhumdev.2005.07.013.

4. Massaro AN, Govindan RB, Al-Shargabi T, Andescavage NN, Metzler M, Chang T, Glass P, du Plessis AJ. Heart rate variability in encephalopathic newborns during and after therapeutic hypothermia. J Perinatol. 2014; 34(11):836-41. https://doi.org/10.1038/jp.2014.108.

5. Griffin MP, Scollan DF, Moorman JR. The dynamic range of neonatal heart rate variability. J Cardiovasc Electrophysiol. 1994:5(2):112-24.

6. Griffin MP, Lake DE, Moorman JR. Heart rate characteristics and laboratory tests in neonatal sepsis. Pediatrics. 2005;115(4):937-41. https://doi.org/10. 1542/peds.2004-1393.

7. Fairchild KD, Schelonka RL, Kaufman DA, et al. Septicemia mortality reduction in neonates in a heart rate characteristics monitoring trial. Pediatr Res. 2013;74(5):570-5. https://doi.org/10.1038/pr.2013.136.

8. Butera G, Bonnet D, Sidi D, Kachaner J, Chessa M, Bossone E, Carminati M, Villain E. Patients operated for tetralogy of Fallot and with non-sustained ventricular tachycardia have reduced heart rate variability. Herz. 2004;29(3): 304-9. https://doi.org/10.1007/s00059-004-2501-8.

9. Faye PM, De Jonckheere J, Logier R, Kuissi E, Jeanne M, Rakza T, Storme L. Newborn infant pain assessment using heart rate variability analysis. Clin J Pain. 2010;26:777-82. https://doi.org/10.1097/AJP.0b013e3181ed1058.

10. Snedec N, Simoncic M, Klemenc M, Ihan A, Vidmar I, Grosek S. Heart rate variability of transported critically ill neonates. Eur J Pediatr. 2013;172(12): 1565-71. https://doi.org/10.1007/s00431-013-2081-9.

11. Nejc Snedec. Analiza variabilnosti srčne frekvence pri kritično bolnih novorojenčkih :PhD thesis. Univerza v Ljubljani, Medicinska fakulteta 2017. https://repozitorij.uni-lj.si//zpisGradiva.php?lang=slv\&id=92682.

12. Wong FY, Witcombe NB, Yiallourou SR, Yorkston S, Dymowski AR, Krishnan L, Walker AM, Horne RS. Cerebral oxygenation is depressed during sleep in healthy term infants when they sleep prone. Pediatrics. 2011;127(3):e558-65. https://doi.org/10.1542/peds.2010-2724.

13. Bembich S, Oretti C, Travan L, Clarici A, Massaccesi S, Demarini S. Effects of prone and supine position on cerebral blood flow in preterm infants. J Pediatr. 2012;160(1):162-4. https://doi.org/10.1016/j.jpeds.2011.08.056.

14. Hunt CE, Hauck FR. Sudden infant death syndrome. CMAJ. 2006;174(13): 1861-9. https://doi.org/10.1503/cmaj.051671.

15. Fyfe KL, Yiallourou SR, Wong FY, Odoi A, Walker AM, Horne RS. Cerebral oxygenation in preterm infants. Pediatrics. 2014. https://doi.org/10.1542/ peds.2014-0773.

16. Yiallourou SR, Walker AM, Horne RS. Prone sleeping impairs circulatory control during sleep in healthy term infants: implications for SIDS. Sleep. 2008;31(8):1139-46.

17. Antila KJ, Valimaki IA, Makela M, Tuominen J, Wilson AJ, Southall DP. Heart rate variability in infants subsequently suffering sudden infant death syndrome (SIDS). Early Hum Dev. 1990. https://doi.org/10.1016/03783782(90)90080-3. 
18. Galland BC, Taylor BJ, Bolton DP. Prone versus supine sleep position: a review of the physiological studies in SIDS research. J Paediatr Child Health. 2002;38(4):332-8. https://doi.org/10.1046/j.1440-1754.2002.00002.x.

19. Ariagno RL, Mirimiran M, Adams MM, Saporito AG, Dubin AM, Baldwin RB. Effect of position on sleep, heart rate variability and QT intveral in preterm infants at and 3 months' corrected age. Pediatrics. 2003:111:622-5.

20. Barbeau DY, Weiss MD. Sleep disturbances in newborns. Children. 2017. https://doi.org/10.3390/children4100090.

21. Klemenc M, Štrumbelj E. Predicting the outcome of head-up tilt test using heart rate variability and baroreflex sensitivity parameters in patients with vasovagal syncope. Clin Auton Res. 2015;25(6):391-8. https://doi.org/10. 1007/s10286-015-0318-6.

22. Malliani A, Pagani M, Montano N, Mela G. Sympathovagal balance: a reappraisal. Circulation. 1998;98(23):2640-3.

23. Malliani A. The pattern of Sympathovagal balance explored in the frequency domain. News Physiol Sci. 1999;14(June):111-7 http://www.ncbi.nlm.nih. gov/pubmed/11390833.

24. Malik M, Bigger J, Camm A, Kleiger R. (1996) Heart rate variability. Standards of measurement, physiological interpretation, and clinical use. Task force of the European Society of Cardiology and the north American Society of Pacing and Electrophysiology. Eur Heart J. 17:354-381. doi:0195-668X/96/ $030354+28$.

25. Benjamini $Y$, Yekutieli $D$. The control of the false discovery rate in multiple testing under dependency. Ann Stat. 2001;29:1165-88. https://doi.org/10. 1214/aos/1013699998.

26. Javorka K, Lehtoska Z, Kozar M, Uhrikova Z, Kolarovszki B, Javorka M, Zibolen M. Heart rate variability in newborns. Physiol Res. 2017;66:203-14.

27. Haskova K., Javorka M., Czippelova B., Zibolen M., Javorka K. (2017) Baroreflex sensitivity in premature infants - relation to the parameters characterizing intrauterine and postnatal condition. Physiol res. (66):257-264.

28. Gournay V, Drouin ERJ. Development of baroreflex control of heart rate in preterm and full term infants. Arch Dis Child Fetal Neonatal Ed. 2002;(86): 151-4.

29. Longin E, Gerstner T, Schaible T, Lenz T, König S. Maturation of the autonomic nervous system: differences in heart rate variability in premature vs. term infants. J Perinat Med. 2006:34(4):303-8. https://doi.org/10.1515/ JPM.2006.058

30. Tuladhar R, Harding R, Michael Adamson T, Horne RS. Comparison of postnatal development of heart rate responses to trigeminal stimulation in sleeping preterm and term infants. J Sleep Res. 2005;14(1):29-36. https://doi. org/10.1111/j.1365-2869.2004.00434.x.

31. Bar-Haim Y, Marshall PJ, Fox N. (2000) Developmental changes in heart period and high-frequency heart period variability from 4 months to 4 years of age. Dev Psychobiol 37(1):44-56. doi:https://doi.org/10.1002/10982302(200007)37:1<44::AID-DEV6>3.0.CO;2-7 [pii].

32. Gabai N, Cohen A, Mahagney A, Bader D, Tirosh E. Arterial blood flow and autonomic function in full-term infants. Clin Physiol Funct Imaging. 2006; 26(2):127-31. https://doi.org/10.1111/j.1475-097X.2006.00661.X.

33. Jean-Louis M, Anwar M, Rosen H, Craelius W, Hiatt M, Hegyi T. Power spectral analysis of heart rate in relation to sleep position. Biol Neonate. 2004:86(2):81-4. https://doi.org/10.1159/000077782.

34. Galland BC, Reeves G, Taylor BJ, Bolton DPG. Sleep position, autonomic function, and arousal. Arch Dis Child Fetal Neonatal Ed. 1998;78(3). https:// doi.org/10.1136/fn.78.3.F189.

35. Gouna G, Rakza T, Kuissi E, Pennaforte T, Mur S, Storme L. (2013) Positioning effects on lung function and breathing pattern in premature newborns. J Pediatr. 162(6):1133-1137, 1137.e1.doi:https://doi.org/10.1016/j.jpeds.2012.11. 036.

36. Warren JB, Anderson JM. Newborn respiratory disorders. Pediatr Rev. 2010. https://doi.org/10.1542/pir.31-12-487.

37. Reuter S, Moser C, Baack M. (2014) Respiratory distress in the newborn. Pediatr Rev 35(10):417-ss428

38. Yang TF, Kao NT, Chan RC, Kuo TBJCA. Power spectrum analysis of heart rate variability in full term and preterm babies. Tw J Phys Med Rehabil. 2007;35(3):127-35.

39. Nagy E, Orvos H, Bárdos G, Molnár P. Gender-related heart rate differences in human neonates. Pediatr Res. 2000;47(June 2000):4-7 http://www.nature. com/pr/journal/v47/n6/abs/pr2000133a.html.

40. Cardoso S, Silva M, Guimarães $H$. Autonomic nervous system in newborns: a review based on heart rate. Childs Nerv Syst. 2017:33(7):1053-63.
41. Selig FA, Tonolli ER, Silva EV, Godoy MF. Heart rate variability in preterm and term neonates. Arq Bras Cardiol. 2011;96(6):443-9. https://doi.org/10.1590/ S0066-782X2011005000059.

42. Chatow U, Davidson S, Reichman BL, Akselrod S. Development and maturation of the autonomic nervous system in premature and full-term infants using spectral analysis of heart rate fluctuations. Pediatr Res. 1995;37: 294-302. https://doi.org/10.1203/00006450-199503000-00008.

43. Friedman WF, George BL. Treatment of congestive heart failure by altering loading conditions of the heart. J Pediatr. 1985;106:697-706. https://doi.org/ 10.1016/S0022-3476(85)80339-5.

44. Zhao F, Li M, Jiang Z, Tsien JZ, Lu Z. Camera-based, non-contact, vital-signs monitoring technology may provide a way for the early prevention of SIDS in infants. Front Neurol. 2016. https://doi.org/10.3389/fneur.2016.00236.

\section{Publisher's Note}

Springer Nature remains neutral with regard to jurisdictional claims in published maps and institutional affiliations.
Ready to submit your research? Choose BMC and benefit from:

- fast, convenient online submission

- thorough peer review by experienced researchers in your field

- rapid publication on acceptance

- support for research data, including large and complex data types

- gold Open Access which fosters wider collaboration and increased citations

- maximum visibility for your research: over $100 \mathrm{M}$ website views per year

At BMC, research is always in progress.

Learn more biomedcentral.com/submission 